\title{
Tourism and the new generations: emerging trends and social implications in Italy
}

\author{
Salvatore Monaco
}

\begin{abstract}
Purpose - The purpose of this paper is to outline the profile of Italian tourists belonging to the new generations: Millennials or Generation Y (approximately people born in the 1980-1995 period) and postMillennials or Generation Z (approximately people born in the 1996-2010 period).

Design/methodology/approach - After reviewing some of the more interesting research on Millennials and post-Millennials, the paper will present the results of an unpublished online empirical survey conducted on a sample of 200 Italian web users who agreed to participate. The questionnaire, administered via computer-assisted web interviewing system, consists of structured questions concerning the practices, attitudes, emerging needs and use of new technologies that characterize Millennials and post-Millennials, with a special focus on tourism.

Findings - The research will consider the differences between the two groups, as well as possible differences within each group linked to other socio-demographic variables (such as gender and area of residence).

Originality/value - The paper addresses a series of innovative questions: what are the practices of Millennials and Post-Millennials as tourists? What are the needs of these generations that the tourist industry must respond to? How do new technologies support Millennials and post-Millennials in their tourism choices? What are the main differences between Millennials and post-Millennials?
\end{abstract}

Keywords Tourism, Millennials, Italy, Generations, Gen Z, Post-Millennials

Paper type Research paper

\section{Introduction}

As widely theorized in social sciences, in postmodern society, tourism and leisure time are no longer a residual part of life (Urry, 2002; Lanfant et al., 2009; Wearing et al., 2010; Dujmović and Vitasović, 2015). Instead, they are high-value activities that contribute to the construction of the identity of social actors (Rojek, 1993; Stebbins, 2007; Nocifora, 2008; Urry and Larsen, 2012). Echoing the words of French anthropologist Marcel Mauss, we may speak of tourism as a "total social fact," a reality capable of generating meaning and providing information on the overall trends in social organization.

Tourism is a dynamic phenomenon, which changes along with other social transformations (Romita, 2000; Savelli, 2002). Sociology is therefore called upon to describe the so-called post tourism or tourism of postmodernism (Rojek and Urry, 2002; Williams, 2004) in its various forms, and to try and forecast its future development, the future changes that will involve the tourist industry and the impact of the above on society at large.

New trends and tendencies in tourism can be properly understood only in the context of the structural evolution of society in general. The more significant factors from this perspective, in a Western context, are the globalization process, the development of transport and the ubiquity of communication tools. All these factors have a major impact on the development of new tourism practices.
Salvatore Monaco is based at the Department of Social Sciences, University of Naples Federico II, Naples, Italy.

Received 2 December 2017 Accepted 13 December 2017

(C) Salvatore Monaco. Published by Emerald Publishing Limited. This article is published under the Creative Commons Attribution (CC BY 4.0) licence. Anyone may reproduce, distribute, translate and create derivative works of this article (for both commercial and non-commercial purposes), subject to full attribution to the original publication and authors. The full terms of this licence may be seen at http://

creativecommons.org/licences/by/ 4.0/legalcode 
To study changes in the tourism labor market and draw possible future scenarios, it is paramount to examine the attitudes, motivations and behaviors of the younger tourists, those known as Generation Y or Millennials (people born in the 1980-1995 period) and as Generation Z or post-Millennials - also known as the "Net Generation" or the "post-Millennials" - (people born in the 1996-2010 period). These are the travelers of the future: according to the United Nations World Tourism Organization estimates, in 2020, tourists under the age of 35 will take about 320 million of international trips (WYSE, 2015).

In seeking to describe the characteristics of contemporary tourism and identify possible future scenarios, the present essay seeks to provide answers to a number of questions: what are the favored tourist practices of Millennials and Post-Millennials? What are the emerging needs of these two generations that the tourist industry must necessarily consider? How do new technologies support Millennials and Post-Millennials in their tourist choices and experiences? What are the main differences between these two categories?

To substantiate our answers, the results of an online unpublished empirical survey conducted on a sample of 200 Italian web users between the end of 2016 and the first months of 2017 will be presented.

More specifically, the paper is organized as following. After the present introduction, Section 2 illustrates the subject of the survey and then describes current literature on Millennials and post-Millennials. Section 3 outlines the methodological structure of the research. Section 4 presents the main findings and the most significant differences between Millennials and post-Millennials. Section 5 discusses the practical and social implications of new tourism practices and the strategies that the tourist industry should implement to meet the needs of younger tourists.

The focus of the research is on Italy for two reasons: first, scientific studies on Italian tourists are scarce compared to those on other social phenomena and practically no research has focused specifically on the new generations. Second, in recent years, Italy has undergone major digitization process (Internet World Stats, 2017). Technological innovations in communication and in digital media have contributed to the transformation of traditional categories of knowledge and culture, redefining the perception and practical experience of tourism.

\section{New generations and tourism: an unexplored relationship}

The term "Generation Y" was used for the first time in an article published in 1993 in the American magazine Advertising Age, to refer to western teenagers of the time. In the article it was stressed how members of this generation were distinct from those of the so-called Generation X (those born between 1963 and the end of the 1970s), being more predisposed to communication, media and use of digital technologies. Two years before, sociologists William Strauss and Neil Howe, in their book Generations: The History of America's Future, 1584 to 2069 (1991), had defined Millennials as people born between 1984 and 2004, the teenagers of the new Millennium. According to Strauss and Howe, Generation $Y$ bears many resemblances to the so-called Great Generation (people born from 1901 until 1924), such as a highly developed sense of duty and a strong link to the homeland. The American sociologist Kathleen Shaputis (2004) instead refers to the same demographic cohort as the "Boomerang" or "Peter Pan Generation," a generation characterized by the tendency to increasingly postpone the transition to adulthood, leaving their parents' home late and delaying other defining steps, such as finishing their studies, finding jobs or marrying. The phenomenon is also widespread in Italy, where, according to some authors (Ambrosi and Rosina, 2009), it depends largely on two separated but closely interrelated factors: a lack of interest on part of public institutions, which do not help young people achieve autonomy or enter the job market, and the protective attitude of the families of origin.

Strauss and Howe (2008) discussed the most recent generation, post-Millennials or Generation Z, pointing out that the dividing line between them and Millennials is not clear-cut. What characterizes and distinguishes post-Millennials is that they are digital natives (Prensky, 2001), the real protagonists of the "new mobilities paradigm" (Urry and Sheller, 2006), a generation characterized by the high mobility of people and things (Urry and Sheller, 2012). 
The life of post-Millennials is deeply influenced by the use of new technologies, to which they have been socialized since childhood (Michael, 2011; Combi, 2015; Pandit, 2015). Along with their familiarity with digital technologies, according to some studies, they are also characterized by an unprecedented awareness and determination as consumers (Koulopoulos and Keldsen, 2016). In the 2020s, they will be the most active players in the tourism market.

\section{Methodological section}

In social sciences, scientific studies on younger generations have dedicated little attention to tourism, focusing instead on fields such as education (Sadker and Sadker, 2005; Seemiller and Meghan, 2016; Bristow, 2016) or work (Walker and Lewis, 2009; Jerome et al., 2014). In particular, in Italy, research on the subject is almost entirely absent. In an effort to elaborate a profile of young Italian tourists and identify emerging trends in tourism, an online survey was carried out. The sample was divided between Millennials and post-Millennials.

The study of trends in travel demand is useful to identify changes taking place in contemporary society. The behaviors and attitudes of social actors influence tourism, and tourism in turn affects society. The very concept of tourism changes, transforms and develops according to social conditioning.

For the purposes of the present survey an ad hoc questionnaire was developed. The survey aims to identify the criteria adopted by Millennials and post-Millennials to make choices and organize one's tourist experience, and identify the priorities of Millennials in regard to tourism, the importance attributed to holidays and their more frequent practices.

In particular, the questions examined are the following:

- The use of ICT in shaping tourist experience. Starting from the assumption according to which both generations are constantly "connected," a specific section of the questionnaire aims to investigate if, and in which way, Millennials and post-Millennials use new technologies, and particularly the web, to organize their holidays.

- Tourist choices: more specifically, what kind of research is done before planning a vacation, which sources are used and so on.

- Tourist behavior and experiences. What do they do during their holidays? What do they seek? How are their needs met?

- Tourism and sharing. We live in a sharing society (Zhao et al., 2011; Walrave et al., 2016). Many aspects of our lives are posted on social networks and made available in real time to followers through post, status, photos, videos and stories. What implications does this kind of behavior have in respect to tourism? What are the most shared contents and why?

The survey was conducted on a sample of 200 self-selected Italian web users equally divided between Millennials and post-Millennials. The questionnaire was administered via computer-assisted web interviewing system (CAWI).

The survey instrument was distributed through major online communication channels (social networks, mailing lists, chat, forum). The decision to use the web as the vehicle for the dissemination of the questionnaire was the result of a series of methodological consideration, and of advantages associated with the use of CAWI[1] (Di Fraia, 2004).

The self-selection of respondents, however, has some implications from a methodological point of view, especially in regard to the representativeness of the sample. Using volunteers basically means resorting to a non-probabilistic sample. As a result, the research is more suited to identifying new trends rather than obtaining inferential results. The data obtained, therefore, are significant but cannot be considered as representative of the entire population.

\section{Results}

Contemporary literature shows that members of Millennials and post-Millennials are accustomed to interacting daily with new technology, and especially internet (Junco and Mastrodicasa, 2007; Gasser and Palfrey; 2008; Veen and Vrakking, 2010; Rosina, 2012). A central role is played by the 
virtual community, of which social networks and platforms for sharing reviews, opinions and information are the most prominent aspect. In the words of Rehingold (1993) "Virtual communities are social aggregations that emerges from the Net when enough people carry on those public discussions long enough, with sufficient human feeling, to form webs of personal relationship in cyberspace" (p. 5).

However, in the area of tourism, in the case of the present survey, the behaviors adopted by the members of the two analyzed generations are in some ways different. Post-Millennials use almost exclusively the web to find the information needed to make purchasing decisions and to make reservations. They query online friends or use contacts they have in social networks. Social networks are often used to share information about personal experiences. They communicate mostly through instant messaging and chat applications. The devices used are almost exclusively mobile (smartphones and tablets). Millennials, instead, while using mobile devices, also make greater use of personal computers. Furthermore, to gather information and make purchasing decisions, they combine the use of internet with more traditional communication tools (such as telephone or magazines). While relying heavily on the information they find online, face-to-face communication still has a major impact on their choices. They are more inclined to trust friends or family than information from websites (see Figure 1).

Still, all respondents reported they pay great attention to online sources. Members of both generations inform themselves in advance on the internet, visiting specific review websites to find information on lodging or restaurants, and may change their plans in the presence of negative feedbacks.

Among the most mentioned sites are www.Booking.com and www.TripAdvisor.com. Founded in 2000 by Stephen Kaufer, TripAdvisor.com is a travel web portal, currently part of Expedia Inc. Family Travel Company, which collects travelers' reviews, often accompanied by photos, of hotels, restaurants and tourist attractions, with a traffic of 32 million visitors per month (Egger et al., 2016). Booking.com is a portal that was created to book hotels, bed and breakfasts and apartments in 96,000 destinations around the world. However, the site, besides for comparing prices and making reservations, is also used to find opinions and reviews by users of the facilities.

The survey also evidenced that while Millennials also read online reviews, they are less inclined to leave their own reviews; post-Millennials instead are more willing to leave reviews and assume a proactive role, playing an important role within a larger communication circuit. In a sense, they are becoming part of the tourist sector, conveying information that if often considered more reliable than that provided by tour operators or suppliers of goods and services.

An aspect that characterizes both generations is the growing tendency in the tourism sector toward collaborative consumption. It is an economic and social activity involving online transactions

Figure 1 Sources used for tourism choices

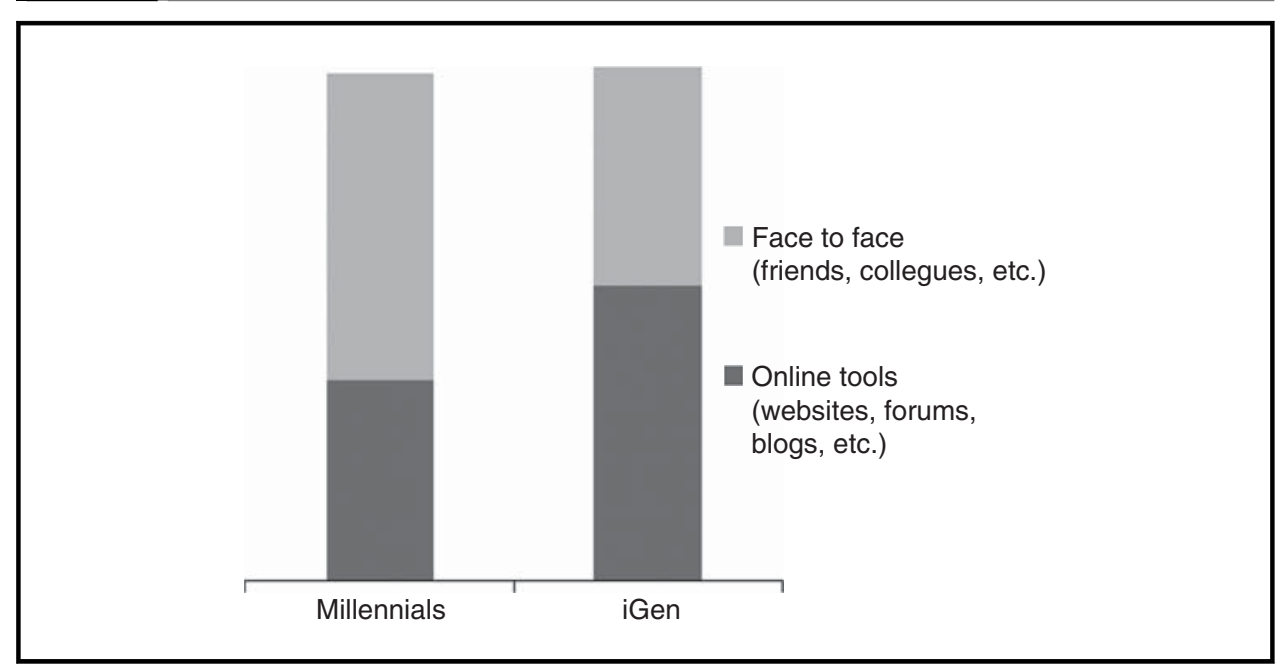


through which social actors share goods, resources and services (Hamari et al., 2016). The increased connectivity ensured by online social network platforms, "allows people to share access to products and services among each other" (Tussyadiah and Inversini, 2015, p. 817). Accessing specific platforms, users meet in a sort of virtual market.

A highly successful service in this shared economy is AirBnB, a portal that brings together supply and demand for short period stays. The portal allows users to rent an apartment or rooms or even exchange apartments with other users.

As for the use of these platforms, interestingly, the results suggest that generation membership is not the variable that has the greatest impact on the choice of whether to use these services or not, and other variables have a greater impact. One such variable is geographical location, with people from the north of Italy making greater use of these platforms, whereas as one moves toward the south, the interest in collaborative consumption decreases (see Figure 2).

Another relevant variable is gender, with males using these platforms more than females. Women seem more reluctant to uses the possibilities offered by the sharing economy, due to the fear of running into scams or other problems.

New technologies have made possible the customization of tourist experiences. Young travelers, both Millennials and Post-Millennials, consider contemporary tourism as a social and cultural experience that encourages socialization and identity construction, giving new meaning to their choices as tourists. Holidays are planned according to their taste and expectations, with a growing interest in new tourism practices and niche proposals.

A marginal, but interesting, result is the propensity for virtual travel. Although the idea of tourism is still significantly linked to physical traveling, the younger tourists mention the central role of new media in offering "imaginative" tourist experiences. Virtual travels are capable of connecting people, places and cultures, as telecommunications continue to develop (Castells, 1996).

\section{Tourism 2.0: social and future implications}

The rise of internet as dominant medium has engendered several significant transformations that affect the tourist experience and will condition the future development of the sector, in terms of both demand and supply. Borrowing from computer terminology, we can refer to this emerging tourism as "tourism 2.0," a new form of tourism characterized by changes in some of its basic features.

The survey conducted on Italian members of Generations $Y$ and $Z$ confirmed that the rise of internet is eroding the mass tourism model. The research results line up with recent studies, which state that today there are several different tourism practices, increasingly independent from class membership. Tourists are more knowledgeable than in the past and are more capable of

Figure 2 Interest in collaborative consumption

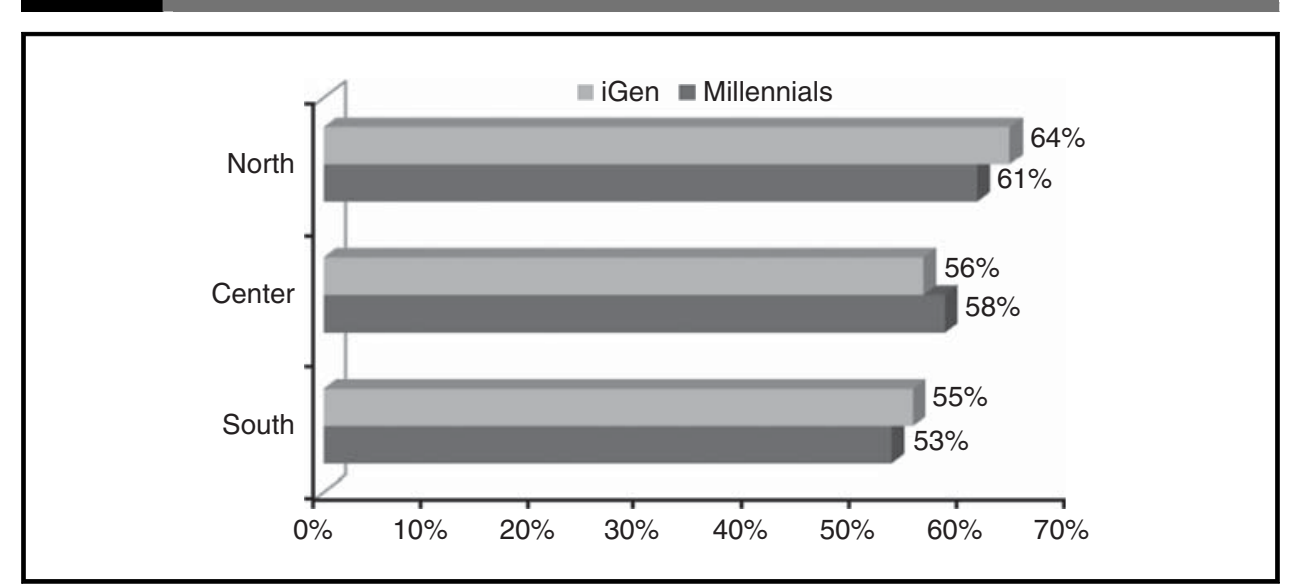


recognizing the lack of authenticity of certain tourist attractions (Savelli, 2002). They are more conscious and independent and see the tourist experience as a useful tool for the construction of their identities (Larsen and Urry, 2016).

The results indicate that the new generations have new social needs that "holidays" are expected to satisfy. Holidays are no longer solely considered as an escape from daily routine, or solely as leisure time, even though these aspects continue to exist. Instead, they are increasingly seen as an instrument associated with culture, discovery and the construction of identity. This development is attributable, among other things, to the amount of information available on the web. News and information present on sites and shared with contacts via chat and social networks fuel the need to broaden the horizons and the experience of web users. Web 2.0 is a source of shared, user-created information that anyone can access with a few clicks, according to their expectations and interests, leading to an increase of what Granovetter (1973) called "strength of weak ties." These ties do not occupy a central place in the social network of individuals, but play a key role in intermediation and in the achievement of their objectives. For tourists interested in expanding their identity, relying on weak ties is very useful to open new horizons, beyond their network of friends.

The results evidence a trend from undifferentiated mass tourism to more variable custom-tailored experiences. New generations see trips as tools capable of enriching them, of having an impact on their lives, on their identities. Young tourists are curious to come into contact with other realities; they are interested in discovering different cultures in line with their own tastes. They are increasingly accustomed to independently organizing their holidays and are very demanding in regard to the tourist offer.

With the advent of mass media before and new media later fashions, consumption tendencies and "other" affiliations have blurred the borders between traditional stratifications. While it is true, as Hebdige (1979) notes, that belonging to a group influences one's lifestyle and consumption patterns, which serve as distinguishing marks of one's identity, it is also true that today the boundaries between groups seem to have become much more mobile.

Taste is no longer linked to spatial and temporal boundaries and to traditional socialization processes but it is increasingly linked to the discoveries that take place through digital media. Nowadays, digital media enable users to access to content globally. With the web, an extensive range of previously excluded destinations and tourist experiences has the opportunity to achieve visibility, encouraging a true global competition in tourism. Globalization and localization, therefore, appear as complementary and integrated phenomena allowing tourists to appreciate local features at an international level. The web encourages contaminations between subcultures and the discovery of social and cultural groups different from one's own, making the boundaries of social memberships more flexible. These cultural trends stimulate new tourist practices which in turn reinforce these trends.

New technologies have made more evident what Rojek (1995) theorized. Over 20 years ago, Rojek argued that people construct their identities through leisure time activities, of which tourism is a significant and growing part. There are various factors that have led to the increasing importance of free time in the lives of individuals. One of these is the increase in unemployment, which has created a surplus of time not devoted to work activities; another is the flexibility introduced in production processes (Échange et projets, 1980), which has changed the structure of individual time and social rhythms. Another aspect confirmed by our survey is the role of the web in a multidimensional process that includes expectations, planning, anticipation of the tourist experience, sharing, memories and comments.

Web 2.0 has turned young tourists into leading actors of the tourist industry. Internet is increasingly used, especially by post-Millennials, not only to benefit from the available content, but also to produce information and materials: memories, reports, reviews, opinions, descriptions and stories. These elements combine with the information generated by tour operators to complete the description of travel destinations. The role of prosumers assumed by tourists has two consequences: it induces actors of the tourist industry to offer more information and it makes it possible to verify the reliability of that information comparing it with other sources.

For the future, it seems more and more important for tourist operators to work strategically and transparently ensuring the quality and veracity of the information content they produce. It is

\begin{tabular}{l|l|l} 
PAGE 12 & JOURNAL OF TOURISM FUTURES & VOL. 4 NO. 12018
\end{tabular} 
increasingly crucial that hoteliers, restaurateurs and retailers communicate truthfully and that they take into account what is said about them on non-official communication channels, such as review sites and social networks. Opinions and reviews should be the starting points for implementing corrective actions and innovations.

In addition, new generations are getting more and more accustomed to getting the information they need in real time. So, operators in the tourist industry should socialize using instant messaging channels (such as WhatsApp, Instagram or Snapchat) to activate a smart and push communication system with customers. These will be the main communication tools of the future, gradually replacing websites, newsletters and other unidirectional information channels.

On a final note, I would observe that the results of the present study confirm yet another fledging trend in the tourist experience: the rise of virtual reality. Emerging forms of mobility are impinging on the equation between tourism and physical movement. We are at the beginning of a change in the traditional perception of tourism in favor of a virtual mobility, made possible by the spread of media and digital devices, in a sort of "second life" in which tourists are the avatar of themselves. Virtual travel seems ready to become the new thing, offering new possibilities and imaginative experiences. Some of the major IT companies are already moving in this direction. In the last few years, we have been enjoying the possibility thanks to Google Maps to virtually walk around the streets of cities throughout the globe. But we are now seeing a growing market for helmets or masks for 3D vision. These can connect to smartphones offering in mixed reality the opportunity to experience exciting virtual travels on the move.

In 2013, Google launched Google Glasses, a device for augmented reality. Google Glasses, manufactured by Luxottica, were a pair of glasses equipped with high-resolution screen, camera and Bluetooth wireless technology. The navigator of Google Glass could project the directions on the lens of the glasses overlapping with what the user was seeing. High price and poor design made the product a flop, and it was withdrawn from the market in 2015, with the promise from Google of a more functional and attractive release soon. In 2016, Samsung launched the Samsung Gear VR device, as similar product at a more affordable price. Like Google Glasses, Gear VR allows users to superimpose virtual content on the real world by overlaying elements such as images and video. On some of the latest mobile phones, it is also possible to enjoy sensational visual experiences. One of the most downloaded applications among those that allow you to travel around the world from the comfort of your home couch is Orbulus. The app offers a 360-degree view of major monuments and tourist attractions of the world, using a gallery of images created with Google Photo Sphere. In Italy, a number of apps have been developed, such as the Hermes virtual tour, which offers the possibility of using augmented reality to visit national archeological sites such as Pompeii or Herculaneum, with the support of an audio guide in over 30 languages. MSC Crociere, an Italian cruise company, has recently created a catalog that offers the opportunity to visit places through augmented reality, turning a traditional activity into a highly innovative and technological one. The strength of the virtual tourist experience is that it overcomes two major limitations of physical travel: cost and safety. Virtual reality has a much lower cost than physical travel, especially when dealing with far-away exotic locations. Also, virtual reality allows tourists to experience realities, even extreme realities, which they would otherwise avoid for fear of accidents, terrorism or even simply lack of comfort.

\section{Conclusion}

We are living in a moment of growth and democratization of tourist experiences. While in the past, travel was restricted to the upper classes, even in the west, nowadays with the development of low-cost travel and collaborative forms of consumption, the possibility of tourism is extending to all sectors of society. In this context, the members of the younger generations are exploiting the potential offered by new digital technologies and communication, using them to promote, construct and interpret specific paths of meaning. The emergence of information society is a crucial development affecting the demand for tourist services, orienting it in the direction of mobility and individualism, a phenomenon of great importance for the sociology of tourism, which will become even more crucial in the future. 


\section{Note}

1. Through the self-administration, the collection of the information is quick and inexpensive and allows neutral feedback because it does not have the presence of the interviewer. In particular, subjects show greater propensity to release information sometimes perceived as confidential or sensitive, that might be reluctant to give to an interlocutor. This prevents distortion and social desirability bias. The respondent also does not live the pressure questionnaire delivery choosing the most appropriate time for compilation taking all the time he needs to think about every single item. The software used gives respondents the possibility to scroll the questionnaire if they need to correct an answer of already placed question. Other advantages are represented by the fact that the information entered in the software is already inserted inside the matrix for the analysis of the data. In addition, on the data that are saved in real time during the fill in process the system runs directly consistency checks between the answers.

\section{References}

Ambrosi, E. and Rosina, A. (2009), L'Italia non è un paese per giovani, Marsilio, Venice.

Bristow, J. (2016), The Sociology of Generations: New Directions and Challenges, Palgrave Macmillan, Basingstoke.

Castells, M. (1996), The Rise of the Network Society, Blackwell, Oxford.

Combi, C. (2015), Generation Z: Their Voices, Their Lives, Windmill Books, London.

Di Fraia, G. (Ed.) (2004), E-research. Internet per la ricerca sociale e di mercato, Laterza, Rome.

Dujmović, M. and Vitasović, A. (2015), "Postmodern society and tourism", Journal of Tourism and Hospitality Management, Vol. 3 Nos 9-10, pp. 192-203.

Échange et projets (1980), La révolution du temps choisi, Albin Michel, Paris.

Egger, R., Gula, I. and Walcher, D. (2016), Open Tourism: Open Innovation, Crowdsourcing and Co-Creation Challenging the Tourist industry, Springer, New York, NY.

Gasser, U. and Palfrey, J. (2008), Born Digital - Connecting with a Global Generation of Digital Natives, Perseus Publishing, New York, NY.

Granovetter, M. (1973), “The strength of weak ties”, American Journal of Sociology, Vol. 78 No. 6, pp. 1360-80.

Hamari, J., Sjöklint, M. and Ukkonen, A. (2016), "The sharing economy: why people participate in collaborative consumption”, Journal of the Association for Information Science and Technology, Vol. 67 No. 9, pp. 2047-59.

Hebdige, D. (1979), Subculture. The Meaning of Style, Paperback, London.

Internet World Stats (2017), Internet in Europe Stats,Miniwatts Marketing Group, Bogotà.

Jerome, A., Scales, M., Whithem, C. and Quain, B. (2014), "Millennials in the workforce: gen Y workplace strategies for the next century", e-Journal of Social \& Behavioural Research in Business, Vol. 5 No. 1, pp. 1-12.

Junco, R. and Mastrodicasa, J. (2007), Connecting to the Net.generation: What Higher Education Professionals Need to Know about Today's Students, NASPA, Washington, DC.

Koulopoulos, T. and Keldsen, D. (2016), The Gen Z Effect: The Six Forces Shaping the Future of Business, Routledge, London.

Lanfant, M.F., Allcock, J. and Bruner, E. (2009), International Tourism Identity and Change, Sage Publications, London.

Larsen, J. and Urry, J. (2016), Mobilities, Networks, Geographies, Routledge, London.

Michael, T. (2011), Deconstructing Digital Natives: Young People, Technology, and the New Literacies, Routledge, London.

Nocifora, E. (2008), La società turistica, Scriptaweb, Naples.

Pandit, V. (2015), We are Generation Z: How Identity, Attitudes, and Perspectives are Shaping our Future, Brown Books Publishing Group, Dallas, TX.

Prensky, M. (2001), "Digital natives, digital immigrants", On the Horizon, Vol. 9 No. 5, pp. 1-6.

Rehingold, H. (1993), The Virtual Community: Homesteading on the Electronic Frontier, MIT Press, Cambridge.

Rojek, C. (1993), Ways of Escape: Modern Transformations in Leisure and Travel, Macmillan, London. 
Rojek, C. (1995), Decentering Leisure: Rethinking Leisure Theory, Sage Publications, London.

Rojek, C. and Urry, J. (Eds) (2002), Touring Cultures. Transformations of Travel and Theory, Routledge, London. Romita, T. (2000), "Argomenti di sociologia del turismo", working paper, University of Calabria, Rende.

Rosina, A. (2012), "I ragazzi delle 3 C", Formiche, Vol. 1 No. 66, pp. 8-9.

Sadker, M. and Sadker, D.M. (2005), Teachers, Schools, and Society, McGraw-Hill, Boston, MA.

Savelli, A. (2002), Sociologia del turismo, FrancoAngeli, Milan.

Seemiller, C. and Meghan, G. (2016), Generation Z Goes to College, Jossey-Bass, Hoboken, NJ.

Shaputis, K. (2004), The Crowded Nest Syndrome: Surviving the Return of Adult Children, Clutter Fairy Publishing, Olympia.

Stebbins, R.A. (2007), Serious Leisure: A Perspective for Our Time, Transaction Publishers, Piscataway, NJ.

Strauss, W. and Howe, N. (1991), Generations: The History of America's Future, 1584 to 2069, Harper Perennial Publisher, New York, NY.

Strauss, W. and Howe, N. (2008), Millennials \& K-12 Schools, LifeCourse Associates, Great Falls.

Tussyadiah, I. and Inversini, A. (2015), Information and Communication Technologies in Tourism, Springer, London.

Urry, J. (2002), The Tourist Gaze, Leisure and Travel in Contemporary Societies, Sage Publications, London.

Urry, J. and Larsen, J. (2012), The Tourist Gaze 3.0, Sage Publications, London.

Urry, J. and Sheller, M. (2006), "The new mobilities paradigm", Environment and Planning, Vol. 38 No. 2, pp. 207-26.

Urry, J. and Sheller, M. (2012), Mobile Technologies of the City, Routledge, London.

Veen, W. and Vrakking, B. (2010), Homo Zappiens. Crescere nell'era digitale, Idea Editrice, Rome.

Walker, J.W. and Lewis, L.H. (2009), Dealing with X, Y, Zs: How to Manage the New Generations in the workplace, FT Press, Upper Saddle River, NJ.

Walrave, M., Ponnet, K. and Vanderhoven, E. (Eds) (2016), Youth 2.0: Social Media and Adolescence. Connecting, Sharing and Empowering, Springer, New York, NY.

Wearing, S., Stevenson, D. and Young, T. (2010), Tourist Cultures: Identity, Place, and the Traveler, Sage Publications, London.

Williams, S. (Ed.) (2004), Tourism: Critical Concepts in the Social Sciences, Routledge, London.

WYSE (2015), "Millennial traveller report”, World Youth Student and Educational Publisher, Amsterdam, January.

Zhao, H.W., Lin, S. and Ray Liu, K.J. (2011), Behavior Dynamics in Media-Sharing Social Networks, Cambridge University, Cambridge.

\section{Further reading}

Euromonitor (2015), Travel in Italy, Euromonitor International, London.

Mauss, M. (1966), The Gift. Forms and Functions of Exchange in Archaic Societies, Cohen \& West, London.

\section{About the author}

Salvatore Monaco is a PhD Student in Statistics and Social Sciences at "Federico II" University in Naples and a Scientific Collaborator of Osservatorio LGBT. His research interests are tourism, technologies and urban contexts with particular focus on gender studies, sexual orientations and generations. He recently published Città arcobaleno (Donzelli, 2017). Salvatore Monaco can be contacted at: salvatore.monaco2@unina.it

For instructions on how to order reprints of this article, please visit our website:

www.emeraldgrouppublishing.com/licensing/reprints.htm

Or contact us for further details: permissions@emeraldinsight.com 